\title{
Multiproduct manufacturer-retailer coordinated supply chain with adjustable rate for common parts, delayed differentiation, and multi-shipment
}

\author{
Hong-Dar Lin ${ }^{\mathrm{a}}$, Victoria Chiu ${ }^{\mathrm{b}}$, Hua-Yao Wu ${ }^{\mathrm{c}}$ and Yuan-Shyi Peter Chiu ${ }^{\mathrm{a}^{*}}$
}

${ }^{a}$ Department of Industrial Engineering \& Management, Chaoyang University of Technology, Taiwan

${ }^{b}$ Department of Accounting, Finance \& Law, The State University of New York at Oswego, New York, USA

${ }^{c}$ Department of Physics, College of Liberal Arts \& Sciences, The State University of New York at Oswego, New York, USA

\section{A B S T R A C T}

Article history:

Received July 18, 2021

Received in revised format

September 21, 2021

Accepted October 142021

Available online

October 142021

Keywords:

Manufacturer-retailer system

Multiproduct

Delayed differentiation

Adjustable-rate

Multi-shipment

\begin{abstract}
Operating in today's turbulent and competitive world marketplaces, manufacturers must find the best production scheme and delivery policy to meet timely client's multiproduct requirements and minimize the total manufacturing-shipment expenses. This study proposes a two-stage delayed differentiation model for a multiproduct manufacturer-retailer coordinated supply chain featuring the adjustable-rate for making common parts and a multi-shipment policy for transporting finished goods. The aim is to help present-day manufacturers achieve their operational goals mentioned above. The mathematical techniques help us build a specific model to explicitly represent the problem and derive its overall operating expense. Then, the convexity of the total expense is verified by Hessian matrix equations. The differential calculus helps derive the cost-minimized fabrication-shipment decision. This study offers an example to demonstrate the applicability and capabilities of our proposed model numerically. The following crucial information has been made available to the managers to facilitate their operating decision makings: (1) the problem's best fabrication-shipment policy; (2) the collective influence of various common part's completion rates and values on the problem's total expenses and optimal fabrication-shipment policy; (3) the impact of various adjustable-rates in stage one on utilization and stage one's uptime; (4) the details of cost contributors to the problem; and (5) the collective impacts of critical features on the problem's performance.
\end{abstract}

\section{Introduction}

Operating in the stiff and turbulent world marketplaces, current manufacturers must find the most efficient and economical supply chain strategy in fabrication schemes and shipping plans to meet timely client multiproduct needs. Implementing a delayed differentiation strategy during the multiproduct making and expediting the time-consuming common parts' producing process helps the manufacturers gain a competitive advantage in system efficiency and overall cost-savings. Arranging the making of numerous products on a single machine can boost its utilization. Schneider and Rinks (1989) considered a periodic-review multi-item storage-space constraint inventory problem with the tradeoff of customer service level and the inventory policy's cost. The researchers derived the system's approximation solution based on asymptotic features from the renewal theorem to meet space constraints, system cost, and workload for arranging customer orders. Katayama (1998) proposed a hierarchical model to evaluate a joined management procedure of mixed lines multiproduct manufacturing system. The presented model considered skilled workers, capable facilities, and tools to allow the efficient production of various products. For the line balancing processes, the researcher proposed an algorithm to minimize the needed stations. For the job sequencing processes, a target chasing approach is used to enable effective and reliable production. The researcher proposed a two-stage hierarchical structure to incorporate the abovementioned procedures and evaluate their

* Corresponding author

E-mail address: ypchiu@cyut.edu.tw (Y.-S. Peter Chiu)

(c) 2022 Growing Science Ltd. All rights reserved.

doi: $10.5267 /$ j.uscm.2021.10.008 
performance with simulated experiments under different situations. Delayed differentiation is an effective manufacturing strategy in planning multi-item production. It makes the standard, intermediate components at one time and fabricates the customized final goods in the second phase to reduce overall manufacturing cost and uptime. Rajagopalan and Swaminathan (2001) presented a coordinated fabrication model to study the collaboration between discrete capacity acquisition and fabrication planning in a constant demand growing/fluctuating situation. The researchers proposed a model using mathematical programming attempting to derive the best acquisition policy of capacity and the optimal fabrication-inventory decision in finite time periods. The results' effectiveness and quality are justified thru computational examples. The influence of manufacturing capacity, capital cost, fabrication decision, and product variety on the optimal solution are investigated to gain crucial managerial insights into the problem. Graman (2010) built a cost minimization model to study the best replenishing levels for end items and postponement strategy in an order-up-to two-product manufacturing environment. The researcher used non-linear programming to solve the model's formulations and gain the optimal inventory and postponement strategies. The author also conducted the sensitivity analyses of the variations in holding, packaging, and postponement costs, fill rate, demand, and product value on the obtained solution. Weskamp et al. (2019) developed a model to investigate the optimal postponement strategy in stochastic-demand supply chains. Their two-stage stochastic model considered integration fabrication and shipment with postponement options, lead times, uncertain demand, shortage cost. The research applied mixed-integer linear programming and used an apparel industry's case to demonstrate their model's applicability. Both risk aversion and the benefits of their proposed model were examined and discussed. Other works (Davis and Sasser, 1995; Nahmias, 2009; Sheikh et al., 2019; Garcia et al., 2020; Chiu et al., 2021; Fatehi-Kivi et al., 2021; Ohmori and Yoshimoto, 2021; Quetschlich et al., 2021; Samuel et al., 2021) considered various features of optimizing manufacturing plans and operations on multiproduct and with postponement alternatives.

Expediting manufacturing/output rate is a commonly used approach to cut down the manufacturing needed time effectively. By adding shifts, applying overtime to an existing shift, or adjusting the machine fabrication rate, manufacturers could expedite their manufacturing/ output rate. Yang et al. (2000) determined the best fabrication and set up schedule for a single machine dual product system considering adjustable fabrication rate. Their study aimed at minimizing the system's setup, backlogging, and average stock-carrying costs. The obtained optimal result was verified by the Hamilton-JacobiBellman equation plus the dynamic programming. Sharma (2008) reexamined an existing work that dealt with the impact of changes in flexible rates on a manufacturing system by adding variations in stock-carrying costs relating to a single or multiproduct replenishing system. The research studied the influence of different carrying-cost scenarios on the system with flexible manufacturing rates. Dellagi et al. (2017) explored smoothing an integrated fabrication-maintenance plan via controlling the manufacturing rate to meet stochastic demand and the needed customer service level. The researchers developed a model to analyze and derive a near-optimal fabrication-maintenance policy considering variable fabrication and failure rates in a finite planning period. The numerical demonstration showed how the model worked and discussed various possible trade-offs consideration. Multiple discontinuous shipments are constantly used in real-world supply chains to move inventories from the manufacturer's warehouse to retailers. Pasandideh et al. (2010) examined a multiproduct economic manufacturing quantity problem featuring orders with discrete shipments, backlogging, and limited spaces. The researchers proposed a genetic algorithm using nonlinear integer programming to solve this problem. Numerical experiments with different variable values and problem sizes are conducted to illustrate the applicability and capability of their proposed model and solution methodology. Inkaya et al. (2018) explored the influence of competition, various costs, and coordination on product price and variety decisions in a producer-customer supply chain environment. The researchers considered costs incurred on the producer's end to be materials, production, storage, and shipping. They examined three scenarios in the supply chain's coordination. They compared them with uncoordinated one to expose (1) the relationship between materials cost and product differentiation strategy and (2) the competitive intensity issue. The authors also conducted numerical experiments to demonstrate the trade-offs of quality level and materials cost. Other works (Brahmi et al., 2020; Nogueira et al., 2020; Tolooie et al., 2020; Astuty et al., 2021; Ekin and Aktekin, 2021; Frank et al., 2021; Martins et al., 2021; Ongcunaruk et al., 2021; Pando et al., 2021) considered various features of adjustable manufacturing rates and discrete shipping plans to optimize fabrication-inventory systems and supply-chain operations. This study proposes a two-stage delayed differentiation model for a multiproduct manufacturer-retailer coordinated supply chain featuring the adjustable-rate for making common parts and a multi-shipment policy for transporting finished goods.

\section{The proposed multiproduct manufacturer-retailer system}

\subsection{Nomenclature}

Notation used in common parts' fabrication (i.e., in stage 1)

$$
\begin{array}{ll}
\lambda_{0} & =\text { annual requirement of common parts, } \\
S_{0} & =\text { setup time } \\
Q_{0} & =\text { lot-size } \\
P_{\mathrm{T} 1,0} & =\text { adjustable rate per year, } \\
t_{1,0} & =\text { uptime when implementing the adjustable-rate, } \\
\alpha_{1,0} & =\text { adding proportion of adjustable-rate, } \\
P_{1,0} & =\text { regular rate }
\end{array}
$$




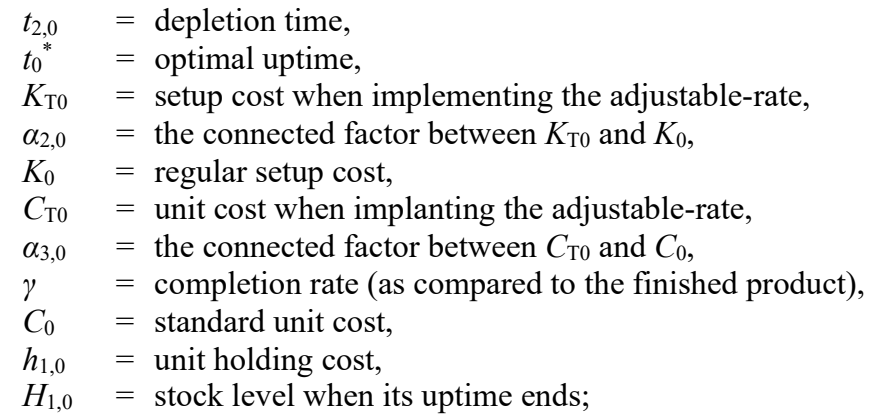

Notation used in finished items' fabrication (i.e., in stage 2)

$\lambda_{i}=$ item $i$ 's requirements per year (where $\left.i=1,2, \ldots, L\right)$,

$L=$ the number of different finished products,

$Q_{i} \quad=$ lot-size,

$S_{i} \quad=$ setup time,

$T_{\mathrm{A}} \quad=$ rotation cycle length - decision variable one,

$P_{1, i} \quad=$ annual manufacturing rate,

$K_{i} \quad=$ setup cost,

$C_{i} \quad=$ unit cost,

$n=$ number of equal-size shipments - decision variable two,

$t_{\mathrm{n}, i}=$ a fixed time-interval between two succeeding shipments,

$t_{1, i}=$ uptime,

$t_{2, i}=$ delivery time,

$t_{\mathrm{i}}^{*}=$ the sum of optimal uptimes (i.e., $\left.\Sigma_{\mathrm{i}}\left(t^{*}{ }_{1, \mathrm{i}}\right)\right)$,

$h_{1, i}=$ unit holding cost,

$i_{0}=$ holding cost ratio (i.e., $h_{1, i}=i_{0} C_{i}$ ),

$H_{1, i} \quad=$ stock level when its uptime ends,

$K_{D, i}=$ fixed transportation cost,

$C_{D, i}=$ unit tranportation cost,

$H_{i} \quad=$ inventory level of common partsl when end item $i$ 's uptime ends,

$I(t)_{i}=$ stock level at time $t$ (where $\left.i=0,1,2, \ldots, L\right)$,

$D_{i} \quad=$ fixed-quantity per delivery,

$T C\left(T_{\mathrm{A}}, n\right)=$ total system cost per cycle,

$I_{\mathrm{c}}(t)_{i}=$ retailer's stock level at time $t$,

$I_{i} \quad=$ number of items left when $t_{\mathrm{n}, i}$ ends,

$\operatorname{TCU}\left(T_{\mathrm{A}}, n\right)=$ the system cost per unit time.

\subsection{Description and modeling}

This study explores a two-stage delayed differentiation multiproduct manufacturer-retailer coordinated system with adjustable-rate for common parts and multi-shipment policy. It extends the multiproduct finite production rate (FPR) model to incorporate postponement strategy with a known constant $\gamma$, an adjustable-rate $P_{\mathrm{T} 1,0}$ for making the common parts in $1^{\text {st }}$ stage, and a multi-shipment rule for transporting the finished goods. Both stages' regular manufacturing rates $P_{1,0}$ and $P_{1, i}$ depend on $\gamma$. For example, if $\gamma=0.5$, then $P_{1,0}$ and $P_{1, i}$ double the single-stage system' normal rates. Additionally, the relationship of adjustable-rate $P_{\mathrm{T} 1,0}$ and regular-rate $P_{1,0}$ and the consequent cost-increase connection are exhibited in the following expressions:

$$
\begin{aligned}
& P_{\mathrm{T} 1,0}=P_{1,0}\left(1+\alpha_{1,0}\right) \\
& K_{\mathrm{T} 0}=K_{0}\left(1+\alpha_{2,0}\right) \\
& C_{\mathrm{T} 0}=C_{0}\left(1+\alpha_{3,0}\right)
\end{aligned}
$$

Fig. 1 depicts the proposed study's stock level. It indicates the stock level upsurges to $H_{1,0}$ as uptime ends. Then, stage two begins to fabricate the finished product $i$, so the common intermediate parts start to deplete. Each finished product $i$ 's inventory level rises to $H_{1, i}$ when their uptime complete (see Figure 1). The proposed system doesn't allow any stock-out occurrences, so formulas $\left(P_{1,0}-\lambda_{0}>0\right)$ and $\left(P_{1, i}-\lambda_{i}>0\right)$ must hold. Based on the assumption of stage two, we observe the following expressions for $i=1,2, \ldots, L$ : 


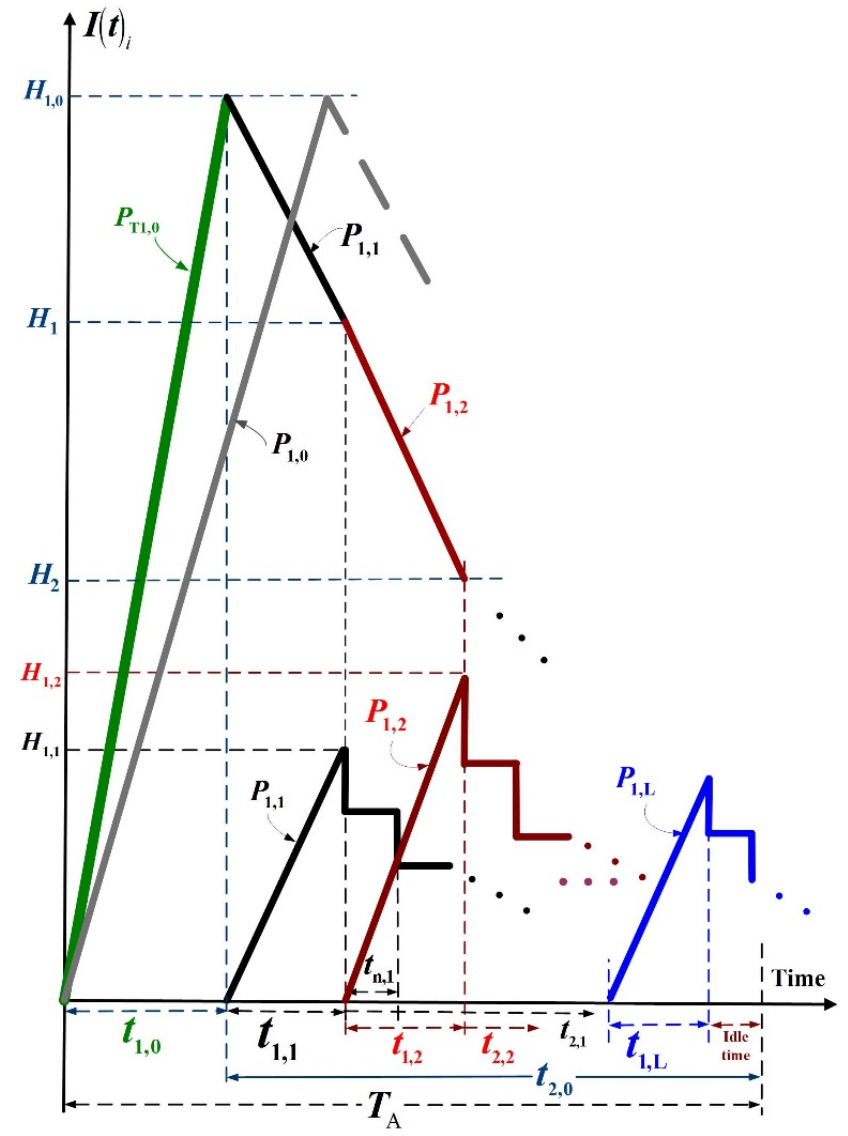

Fig. 1.Stock level of the proposed two-stage multiproduct manufacturer-retailer coordinated system with adjustable-rate for common parts, delayed differentiation, and multi-shipment compared to the same system without adjustable rate (in grey)

$$
\begin{aligned}
& T_{\mathrm{A}}=\frac{Q_{i}}{\lambda_{i}}=t_{1, i}+t_{2, i} \\
& Q_{i}=\lambda_{i} T_{\mathrm{A}} \\
& t_{1, i}=\frac{Q_{i}}{P_{1, i}}=\frac{H_{1, i}}{P_{1, i}} \\
& t_{2, i}=T_{\mathrm{A}}-t_{1, i} \\
& H_{1, i}=Q_{i}=P_{1, i} t_{1, i}
\end{aligned}
$$

According to the assumption of stage one, we know that the common intermediate parts must meet the need for fabricating finished products (as shown in Eq. (9), also refer to Eq. (5)), and the following additional expressions are observed:

$$
\begin{aligned}
& H_{1,0}=\sum_{i=1}^{L} Q_{i}=\sum_{i=1}^{L} \lambda_{i} T_{\mathrm{A}} \\
& T_{\mathrm{A}}=t_{1,0}+t_{2,0} \\
& t_{1,0}=\frac{Q_{0}}{P_{T 1,0}}=\frac{H_{1,0}}{P_{T 1,0}} \\
& \lambda_{0}=\frac{\sum_{i=1}^{L} Q_{i}}{T_{\mathrm{A}}} \\
& H_{1}=H_{1,0}-Q_{1}
\end{aligned}
$$




$$
\begin{aligned}
& H_{i}=H_{(i-1)}-Q_{i}, \text { where } i=2,3, \ldots, L \\
& H_{L}=H_{(L-1)}-Q_{L}=0
\end{aligned}
$$

Fig. 2 illustrates the manufacturer's inventory level in each finished item $i$ 's transporting time, and they are shipped to the retailer under $n$ equal-size shipments in each interval $t_{\mathrm{n}, i}$ time. The total stocks in $t_{2, i}$ is given in Eq. (16):

$$
\left(\frac{1}{n^{2}}\right)\left(\sum_{i=1}^{n-1} i\right) H_{1, i}\left(t_{2, i}\right)=\left(\frac{1}{n^{2}}\right) H_{1, i}\left(t_{2, i}\right)\left[\frac{n(n-1)}{2}\right]=\left(\frac{n-1}{2 n}\right) H_{1, i}\left(t_{2, i}\right)
$$

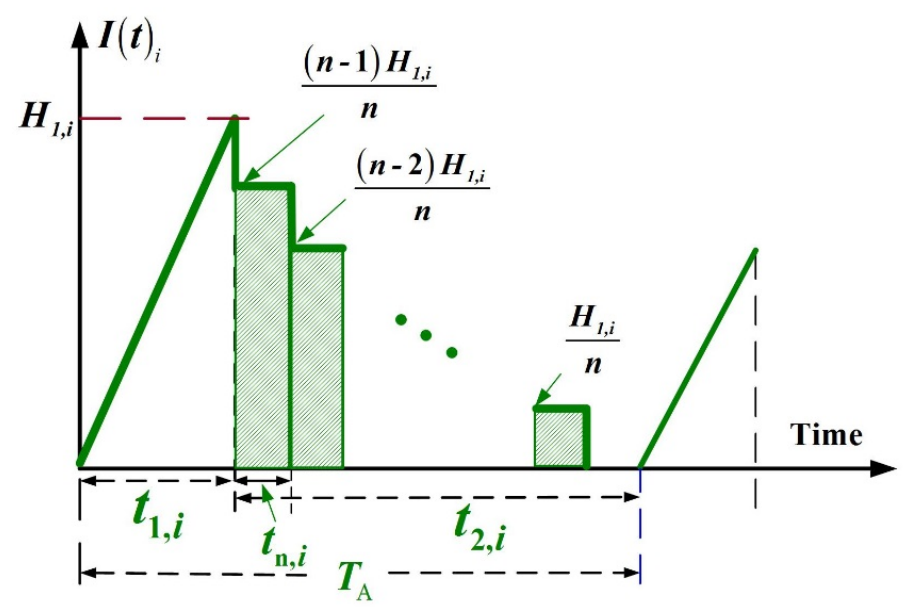

Fig. 2. Manufacturer's finished product $i$ level in shipping time $t_{2, i}$

Fig. 3. demonstrates the retailer's inventory level of each item $i$. The retailer's total stocks are given in Eq. (17):

$$
\left[\frac{n\left(D_{i}-I_{i}\right) t_{n, i}}{2}+\frac{n(n+1)}{2} I_{i} t_{n, i}+\frac{n I_{i}\left(t_{1, i}\right)}{2}\right]
$$

where

$$
\begin{aligned}
& D_{i}=\frac{H_{1, i}}{n} \\
& t_{n, i}=\frac{t_{2, i}}{n} \\
& I_{i}=D_{i}-\lambda_{i}\left(t_{n, i}\right)
\end{aligned}
$$

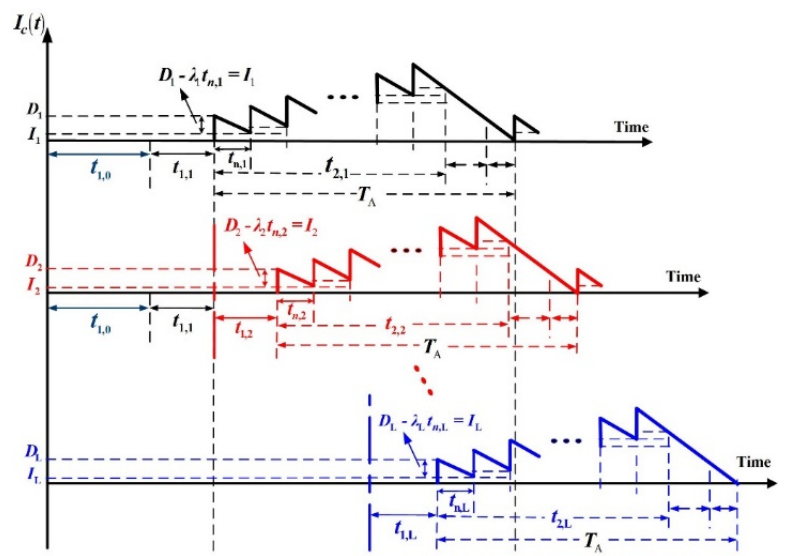

Fig. 3. Retailer's product $i$ level 


\section{Overall system cost and the manufacturing-shipment policy}

\subsection{Overall system cost}

The overall system cost per cycle $T C\left(T_{\mathrm{A}}, n\right)$ includes the following manufacturing-shipment related expenses: (1) variable, (2) setup, (3) finished items' transportation, and (4) inventory holding at both manufacturer and retailer ends:

$$
\begin{aligned}
T C\left(T_{A}, n\right)= & \left\{C_{T 0} Q_{0}+K_{T 0}+h_{1,0}\left[\frac{H_{1,0} t_{1,0}}{2}+\sum_{i=1}^{L}\left[\frac{Q_{i}}{2}\left(t_{1, i}\right)+H_{i}\left(t_{1, i}\right)\right]\right]\right\} \\
& +\sum_{i=1}^{L}\left\{\begin{array}{l}
C_{i} Q_{i}+K_{i}+n K_{D, i}+C_{D, i} Q_{i}+h_{1, i}\left[\frac{H_{1, i} t_{1, i}}{2}+\left(\frac{n-1}{2 n}\right) H_{1, i}\left(t_{2, i}\right)\right] \\
+h_{3, i}\left[\frac{n\left(D_{i}-I_{i}\right) t_{n, i}}{2}+\frac{n(n+1)}{2} I_{i} t_{n, i}+\frac{n I_{i}\left(t_{1, i}\right)}{2}\right]
\end{array}\right\}
\end{aligned}
$$

Substituting Eqs. (1) to (20) in Eq. (21) and computing $T C\left(T_{\mathrm{A}}, n\right) / T_{\mathrm{A}}$, we gain the following $T C U\left(T_{\mathrm{A}}, n\right)$ :

$$
\begin{aligned}
\operatorname{TC} & \left(T_{A}, n\right)=\frac{T C\left(T_{A}, n\right)}{T_{A}}=\left(1+\alpha_{3,0}\right) C_{0} \lambda_{0}+\frac{\left(1+\alpha_{2,0}\right) K_{0}}{T_{A}}+h_{1,0} \sum_{i=1}^{L}\left(\frac{\lambda_{i}^{2} T_{A}}{2 P_{1, i}}\right) \\
& +h_{1,0}\left\{\left[\frac{\lambda_{0}^{2} T_{A}}{2\left(1+\alpha_{1,0}\right) P_{1,0}}\right]+\sum_{i=1}^{L}\left\{-\left(\frac{\lambda_{i} T_{A}}{P_{1, i}}\right)\right\}\left[\sum_{j=1}^{i}\left(\lambda_{j}\right)\right]+\left[\sum_{i=1}^{L}\left(\lambda_{i}\right)\right] \cdot \sum_{i=1}^{L}\left(\frac{\lambda_{i} T_{A}}{P_{1, i}}\right)\right\} \\
& +\sum_{i=1}^{L}\left\{C_{i} \lambda_{i}+\frac{K_{i}}{T_{A}}+\frac{n K_{D, i}}{T_{A}}+C_{D, i} \lambda_{i}+\frac{h_{1, i} \lambda_{i} T_{A}}{2}+\frac{h_{3, i} \lambda_{i}^{2} T_{A}}{2 P_{1, i}}+\frac{\left(h_{3, i}-h_{1, i}\right) \lambda_{i}^{2} T_{A}}{2 n}\left(\frac{1}{\lambda_{i}}-\frac{1}{P_{1, i}}\right)\right\}
\end{aligned}
$$

\subsection{The optimal manufacturing-shipment policy}

Applying the Hessian Matrix Equations $\operatorname{TCU}\left(T_{\mathrm{A}}, n\right)$ (Rardin, 1998), one obtains the following:

$$
\left[\begin{array}{ll}
T_{\mathrm{A}} & n
\end{array}\right] \cdot\left(\begin{array}{ll}
\frac{\partial^{2} T C U\left(T_{\mathrm{A}}, n\right)}{\partial T_{\mathrm{A}}^{2}} & \frac{\partial^{2} T C U\left(T_{\mathrm{A}}, n\right)}{\partial T_{\mathrm{A}} \partial n} \\
\frac{\partial^{2} T C U\left(T_{\mathrm{A}}, n\right)}{\partial T_{\mathrm{A}} \partial n} & \frac{\partial^{2} T C U\left(T_{\mathrm{A}}, n\right)}{\partial n^{2}}
\end{array}\right) \cdot\left[\begin{array}{c}
T_{\mathrm{A}} \\
n
\end{array}\right]=\left\{\frac{2 K_{0}\left(1+\alpha_{2,0}\right)}{T_{A}}+\sum_{i=1}^{L}\left(\frac{2 K_{i}}{T_{A}}\right)\right\}>0
$$

Eq. (23) is positive, for the outcomes of $K_{0},\left(1+\alpha_{2,0}\right), T_{\mathrm{A}}$, and $K_{i}$, are positive. Hence, we prove that $T C U\left(T_{\mathrm{A}}, n\right)$ is strictly c onvex for all $T_{\mathrm{A}}$ and $n>0$. Then, by solving the linear system of $T C U\left(T_{\mathrm{A}}, n\right)$ 's first-derivatives (i.e., Eqs. (24) \& (25)), one derives $T_{\mathrm{A}}{ }^{*}$ and $n^{*}$ :

$$
\begin{aligned}
& \frac{\partial T C U\left(T_{\mathrm{A}}, n\right)}{\partial n}= \sum_{i=1}^{L}\left[\frac{K_{D, i}}{T_{A}}-\frac{\left(h_{3, i}-h_{1, i}\right) \lambda_{i}^{2} T_{A}}{2 n^{2}}\left(\frac{1}{\lambda_{i}}-\frac{1}{P_{1, i}}\right)\right]=0 \\
& \frac{\partial T C U\left(T_{\mathrm{A}}, n\right)}{\partial T_{\mathrm{A}}}=\left\{\begin{array}{l}
\frac{-\left(1+\alpha_{2,0}\right) K_{0}}{T_{A}^{2}}+h_{1,0} \sum_{i=1}^{L}\left(\frac{\lambda_{i}^{2}}{2 P_{1, i}}\right)+h_{1,0}\left[\frac{\lambda_{0}^{2}}{2\left(1+\alpha_{1,0}\right) P_{1,0}}\right] \\
+h_{1,0}\left\{\sum_{i=1}^{L}\left\{-\left(\frac{\lambda_{i}}{P_{1, i}}\right)\right\}\left[\sum_{j=1}^{i}\left(\lambda_{j}\right)\right]+\left[\sum_{i=1}^{L}\left(\lambda_{i}\right)\right] \cdot \sum_{i=1}^{L}\left(\frac{\lambda_{i}}{P_{1, i}}\right)\right\} \\
+\sum_{i=1}^{L}\left\{\frac{-\left(K_{i}+n K_{D, i}\right)}{T_{A}^{2}}+\frac{h_{1, i} \lambda_{i}}{2}+\frac{h_{3, i} \lambda_{i}^{2}}{2 P_{1, i}}+\frac{\left(h_{3, i}-h_{1, i}\right) \lambda_{i}^{2}}{2 n}\left(\frac{1}{\lambda_{i}}-\frac{1}{P_{1, i}}\right)\right\}
\end{array}\right\}=0
\end{aligned}
$$

Therefore, the optimal manufacturing-shipment policy $\left(T_{\mathrm{A}}^{*}, n^{*}\right)$ are found:

$$
T_{\mathrm{A}}^{*}=\sqrt{\frac{2\left[\left(1+\alpha_{2,0}\right) K_{0}+\sum_{i=1}^{L}\left(K_{i}+n K_{D, i}\right)\right]}{h_{1,0} \sum_{i=1}^{L}\left(\frac{\lambda_{i}^{2}}{P_{1, i}}\right)+\sum_{i=1}^{L}\left\{h_{1, i} \lambda_{i}+\frac{h_{3, i} \lambda_{i}^{2}}{P_{1, i}}+\frac{\left(h_{3, i}-h_{1, i}\right) \lambda_{i}^{2}}{n}\left(\frac{1}{\lambda_{i}}-\frac{1}{P_{1, i}}\right)\right\}}}
$$


and

$$
n^{*}=\sqrt{\frac{\left[\left(1+\alpha_{2,0}\right) K_{0}+\sum_{i=1}^{L}\left(K_{i}\right)\right] \cdot \sum_{i=1}^{L}\left[\left(h_{3, i}-h_{1, i}\right) \lambda_{i}^{2}\left(\frac{1}{\lambda_{i}}-\frac{1}{P_{1, i}}\right)\right]}{\left(\sum_{i=1}^{L} K_{D, i}\right)\left\{\begin{array}{l}
h_{1,0} \sum_{i=1}^{L}\left(\frac{\lambda_{i}^{2}}{P_{1, i}}\right)+\sum_{i=1}^{L}\left\{h_{1, i} \lambda_{i}+\frac{h_{3, i} \lambda_{i}^{2}}{P_{1, i}}\right\}+h_{1,0}\left[\frac{\lambda_{0}{ }^{2}}{\left(1+\alpha_{1,0}\right) P_{1,0}}\right] \\
+h_{1,0}\left\{-2 \sum_{i=1}^{L}\left(\frac{\lambda_{i}}{P_{1, i}}\right)\left[\sum_{j=1}^{i}\left(\lambda_{j}\right)\right]+2\left[\sum_{i=1}^{L}\left(\lambda_{i}\right)\right] \cdot \sum_{i=1}^{L}\left(\frac{\lambda_{i}}{P_{1, i}}\right)\right\}
\end{array}\right.}}
$$

\subsection{Discussion on setup times}

In most cases, the total setup times $S_{\mathrm{i}}$ is insignificant to the operating cycle. However, to be on the safe side, one should compute $T_{\min }$ (Nahmias, 2009, also as shown in Eq. (28)) and make sure that $T_{\min }<T_{\mathrm{A}} *$. If not, select $\max \left(T_{\min }, T_{\mathrm{A}} *\right)$ as the operating cycle time.

$$
T_{\min }=\frac{\sum_{i=0}^{L} S_{i}}{1-\left[\frac{\lambda_{0}}{P_{T 1,0}}+\sum_{i=1}^{L}\left(\frac{\lambda_{i}}{P_{1, i}}\right)\right]}
$$

\subsection{Discussion on the machine capacity}

Moreover, for a two-stage multiproduct manufacturing plan, managers should make sure that they have adequate capacity to perform the task in both stages. That is, expressions (29) and (30) must hold (Nahmias, 2009):

$$
\left[\left(t_{1,0}\right)+\sum_{i=1}^{L}\left(t_{1, i}\right)\right]<T_{\mathrm{A}} \text { or }\left[\left(\frac{Q_{0}}{P_{T 1,0}}\right)+\sum_{i=1}^{L}\left(\frac{Q_{i}}{P_{1, i}}\right)\right]<T_{\mathrm{A}}
$$

or

$$
\left[\frac{\lambda_{0}}{P_{T 1,0}}+\sum_{i=1}^{L}\left(\frac{\lambda_{i}}{P_{1, i}}\right)\right]<1
$$

\section{Numerical illustration}

The following example illustrates the proposed multiproduct manufacturer-retailer coordinated system's capability and applicability numerically. Tables 1 and 2 show the assumed parameters' values in stages one and two of our numerical example. Table A-1 (in Appendix A) exhibits the similar system's assumed parameters' values which using a one-stage fabrication scheme for comparison purposes.

\section{Table 1}

Parameters' values assumed in stage 1 of our example

\begin{tabular}{|c|c|c|c|c|c|c|c|c|}
\hline Product $i$ & $K_{D, i}$ & $\lambda_{i}$ & $h_{1, i}$ & $C_{\mathrm{D}, i}$ & $C_{i}$ & $h_{3, i}$ & $P_{1, i}$ & $K_{i}$ \\
\hline 1 & $\$ 1800$ & 3000 & $\$ 16$ & $\$ 0.1$ & $\$ 40$ & $\$ 70$ & 112258 & $\$ 8500$ \\
\hline 2 & $\$ 1900$ & 3200 & $\$ 18$ & $\$ 0.2$ & $\$ 50$ & $\$ 75$ & 116066 & $\$ 9000$ \\
\hline 3 & $\$ 2000$ & 3400 & $\$ 20$ & $\$ 0.3$ & $\$ 60$ & $\$ 80$ & 120000 & $\$ 9500$ \\
\hline 4 & $\$ 2100$ & 3600 & $\$ 22$ & $\$ 0.4$ & $\$ 70$ & $\$ 85$ & 124068 & $\$ 10000$ \\
\hline 5 & $\$ 2200$ & 3800 & $\$ 24$ & $\$ 0.5$ & $\$ 80$ & $\$ 90$ & 128276 & $\$ 10500$ \\
\hline
\end{tabular}

\begin{tabular}{ccccccccccc}
\hline$P_{1,0}$ & $C_{0}$ & $\delta$ & $K_{0}$ & $h_{1,0}$ & $\gamma$ & $\alpha_{1,0}$ & $\lambda_{0}$ & $\mathrm{i}_{0}$ & $\alpha_{2,0}$ & $\alpha_{3,0}$ \\
\hline 120000 & $\$ 40$ & 0.5 & $\$ 8500$ & $\$ 8$ & 0.5 & 0.5 & 17000 & 0.2 & 0.1 & 0.25 \\
\hline
\end{tabular}

Table 2

Parameters' values assumed in stage one of our example

4.1. The convexity of $\operatorname{TCU}\left(T_{\mathrm{A}}^{*}, n^{*}\right)$ and optimal policies

Apply formulas (26), (27), and (22) to derive $T_{\mathrm{A}} *=0.5398, n^{*}=4$, and $T C U\left(T_{\mathrm{A}}^{*}, n^{*}\right)=\$ 2,254,128$. The behavior of $T C U\left(T_{\mathrm{A}}\right.$, 
$n$ ) concerning $T_{\mathrm{A}}$ and $n$ is depicted in Fig. 4. It not only demonstrates the convexity of $T C U\left(T_{\mathrm{A}}, n\right) . E\left[T C U\left(T_{\mathrm{A}}^{*}, n^{*}\right)\right]$ noticeably upsurges as both $T_{\mathrm{A}}$ and $n$ and $T_{\mathrm{A}}$ depart from the optimal values.

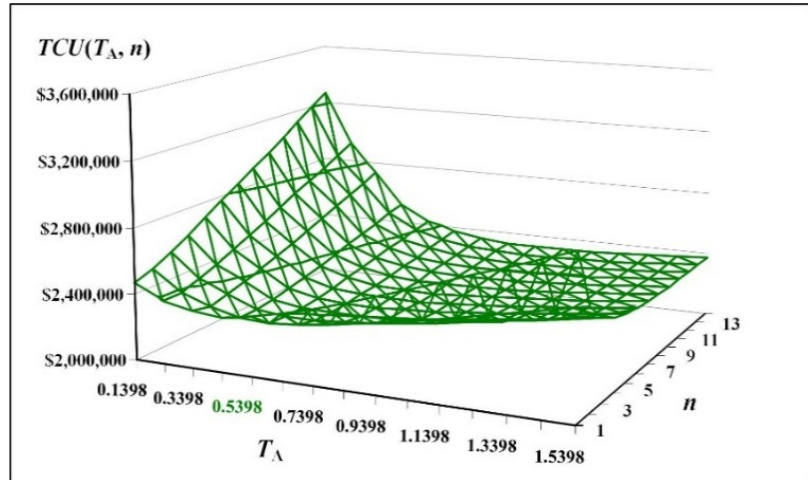

Fig. 4. The behavior of $\operatorname{TCU}\left(T_{\mathrm{A}}, n\right)$ concerning to $T_{\mathrm{A}}$ and $n$

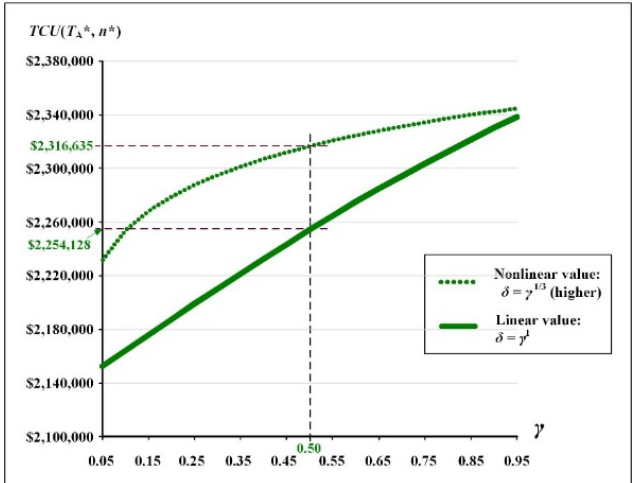

Fig. 5. The behavior $E\left[T C U\left(T_{\mathrm{A}}^{*}, n^{*}\right)\right]$ regarding nonlinear and linear relationships of $\delta$ and $\gamma$

\subsection{The influence of main system's features}

Fig. 5 reveals the impact of nonlinear and linear and relationships of the value $\delta$ and completion rate $\gamma$ on $T C U\left(T_{\mathrm{A}}^{*}, n^{*}\right)$. For the nonlinear case with higher component value (i.e., $\delta=\gamma^{1 / 3}$ ), at $\gamma=0.5$, we find $\operatorname{TCU}\left(T_{\mathrm{A}}{ }^{*}, n^{*}\right)=\$ 2,316,635$. For the linear case (i.e., $\delta=\gamma^{1}$ ), at $\gamma=0.5$, we reconfirm $\operatorname{TCU}\left(T_{\mathrm{A}}^{*}, n^{*}\right)=\$ 2,254,128$. Fig. 6 exposes the behavior of $T_{\mathrm{A}}^{*}$ concerning nonlinear and linear and relationships of $\delta$ and $\gamma$. For the nonlinear case with higher component value, at $\gamma=0.5$, we find $T_{\mathrm{A}}{ }^{*}=0.4192$. For the linear case, at $\gamma=0.5$, we reconfirm $T_{\mathrm{A}}{ }^{*}=0.5398$.

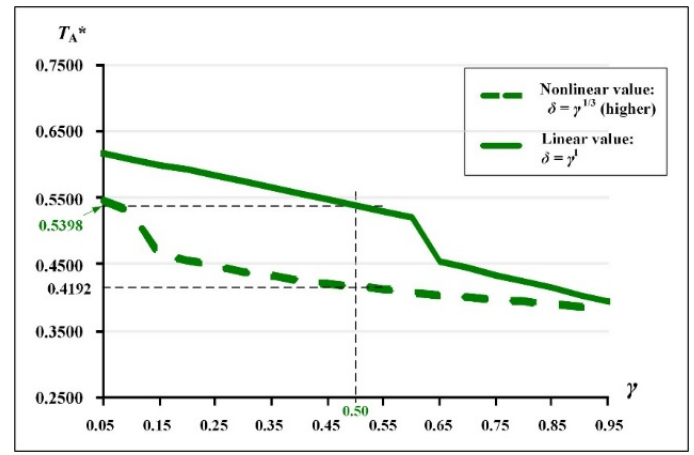

Fig. 6. The behavior $T_{\mathrm{A}}{ }^{*}$ concerning nonlinear and linear relationships of $\delta$ and $\gamma$

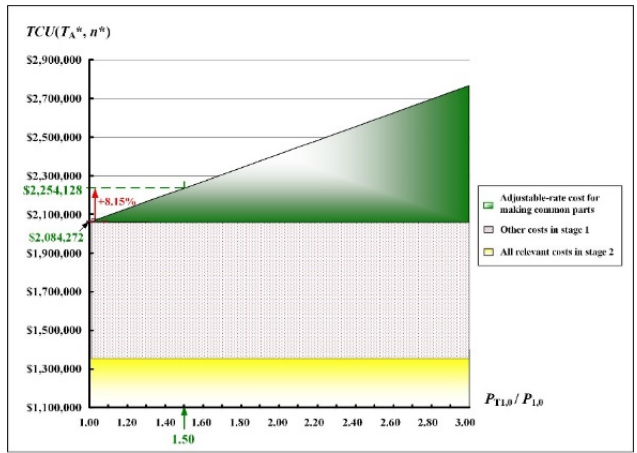

Fig. 7. The impact of $\left(P_{\mathrm{T} 1,0} / P_{1,0}\right)$ on key cost contributors in $\operatorname{TCU}\left(T_{\mathrm{A}}^{*}, n^{*}\right)$

Fig. 7 shows the influence of $\left(P_{\mathrm{T} 1,0} / P_{1,0}\right)$ on key cost contributors in $\operatorname{TCU}\left(T_{\mathrm{A}}^{*}, n^{*}\right)$. As $\left(P_{\mathrm{T} 1,0} / P_{1,0}\right)$ rises, the most influence component is the common parts' adjustable-rate cost. At $\left(P_{\mathrm{T} 1,0} / P_{1,0}\right)=1.5$, it reconfirms $T C U\left(T_{\mathrm{A}} *, n^{*}\right)=\$ 2,254,128$; a 8.15\% increase in $\operatorname{TCU}\left(T_{\mathrm{A}}^{*}, n^{*}\right)$ (i.e., from $\$ 2,084,272$ for the model without implementing adjustable-rate). Fig. 8 investigates the details of $T C U\left(T_{\mathrm{A}}^{*}, n^{*}\right)$ 's cost contributors. The following are the major cost contributors to $T C U\left(T_{\mathrm{A}}^{*}, n^{*}\right)$ in order: (i) variable cost for multiproduct; (ii) the common parts' variable cost; (iii) the common parts' adjustable-rate cost; (iv) the retailer holding cost; (v) setup cost for multiproduct; and (vi) cost of transporting multiproduct; etc.

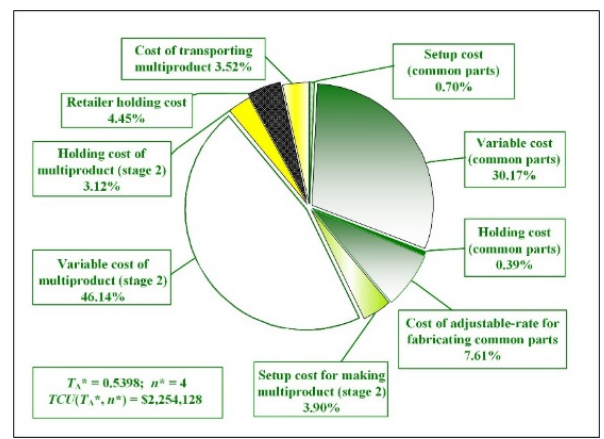

Fig. 8. The details of $\operatorname{TCU}\left(T_{\mathrm{A}}^{*}, n^{*}\right)$ 's cost contributors

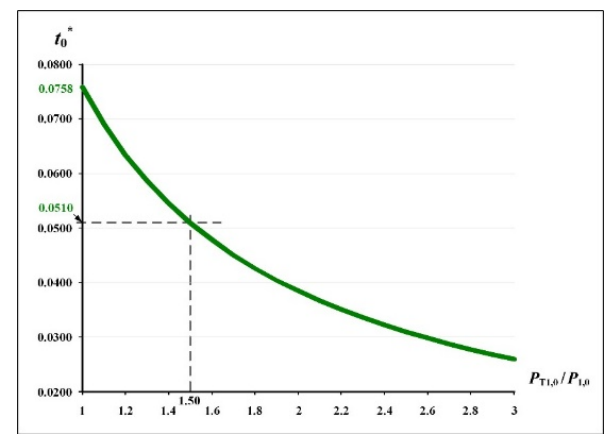

Fig. 9. The ratio $\left(P_{\mathrm{T} 1,0} / P_{1,0}\right)$ effects on $t_{0} *$ 
Fig. 9 depicts $\left(P_{\mathrm{T} 1,0} / P_{1,0}\right)$ impact on $t_{0} *$. At $\left(P_{\mathrm{T} 1,0} / P_{1,0}\right)=1.5, t_{0} *$ drops to 0.0510 (years) from 0.0758 , a $32.72 \%$ decline. Fig. 10 explores the $\left(P_{\mathrm{T} 1,0} / P_{1,0}\right)$ influence on system utilization. At $\left(P_{\mathrm{T} 1,0} / P_{1,0}\right)=1.5$, utilization declines to 0.2357 from 0.2829 , a $16.69 \%$ drop.

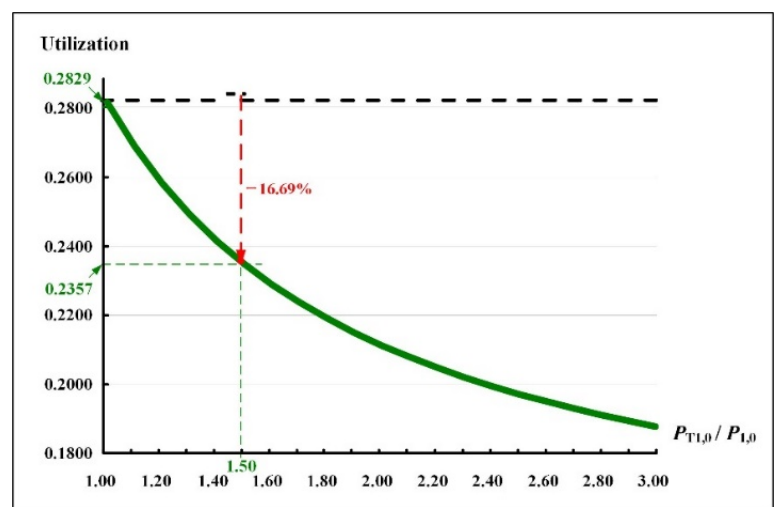

Fig. 10. The influence on utilization concerning $\left(P_{\mathrm{T} 1,0} /\right.$ $\left.P_{1,0}\right)$

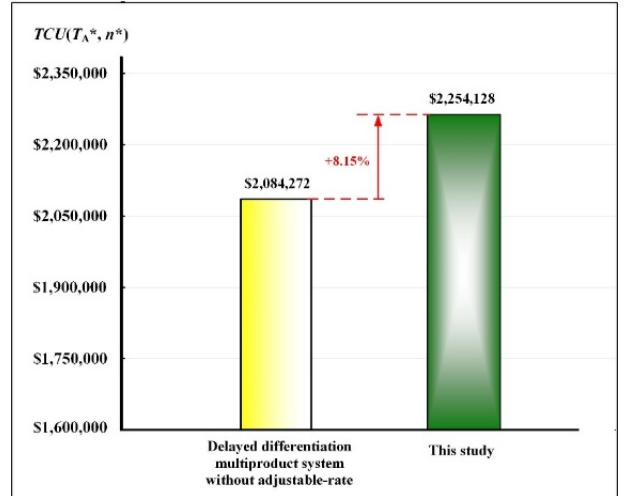

Fig. 11. Comparing our study's $E\left[T C U\left(T_{\mathrm{A}}^{*}, n^{*}\right)\right]$ with that of a closely related model

For a $16.69 \%$ reduction in utilization, this study pays a price of $8.15 \%$ rise in $T C U\left(T_{\mathrm{A}}^{*}, n^{*}\right)$ (i.e., increasing from $\$ 2,084,272$ to $\$ 2,254,128$; as exhibited in Fig. 11). Furthermore, the proposed model can explore other detailed system feature effects on the problem. Fig. 12 displays the adjustable-rate unit cost ratio $\left(C_{\mathrm{T} 0} / C_{0}\right)$ impact on end products' variable cost. It indicates $\left(C_{\mathrm{T} 0} / C_{0}\right)$ ratio has an insignificant influence on each end product's variable cost.

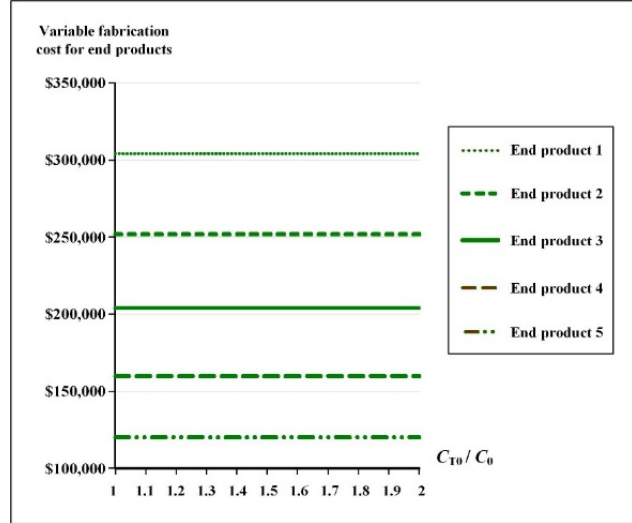

Fig. 12. The ratio $\left(C_{\mathrm{T} 0} / C_{0}\right)$ impact on each end product's variable cost

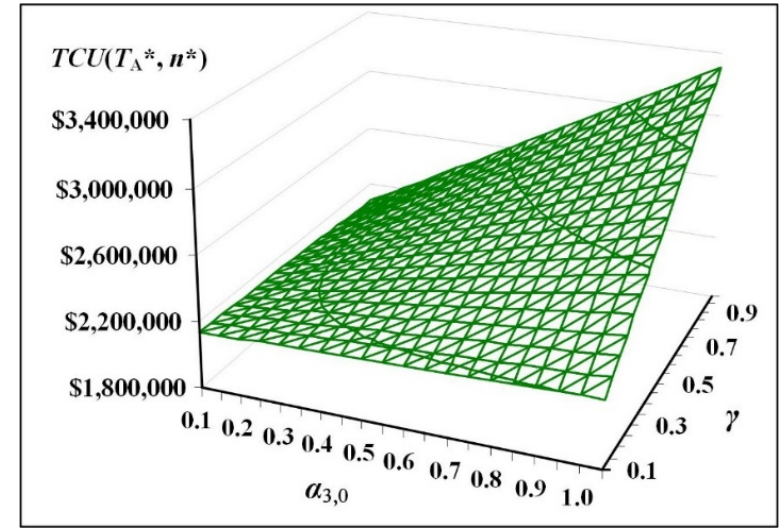

Fig. 13. Behavior of $\operatorname{TCU}\left(T_{\mathrm{A}}^{*}, n^{*}\right)$ relating to $\alpha_{3,0}$ and $\gamma$

\subsection{Collective impact of main system features}

Fig. 13 investigates the collective impact of the adjustable-rate added portion of unit cost $\alpha_{3,0}$ and $\gamma$ on $T C U\left(T_{\mathrm{A}}{ }^{*}, n^{*}\right)$. It shows $T C U\left(T_{\mathrm{A}}^{*}, n^{*}\right)$ varies insignificantly as both $\alpha_{3,0}$ and $\gamma$ stay at the lower values, and $T C U\left(T_{\mathrm{A}}{ }^{*}, n^{*}\right)$ severely surges as both $\alpha_{3,0}$ and $\gamma$ rise higher. Fig. 14 discloses the combined influence of $\gamma$ and the adjustable-rate added output proportion $\alpha_{1,0}$ on $T_{\mathrm{A}} *$. As $\gamma$ rises, $T_{\mathrm{A}} *$ radically declines, and as $\alpha_{1,0}$ increases, $T_{\mathrm{A}}{ }^{*}$ slightly changes. It exposes that $\gamma$ has more impact on $T_{\mathrm{A}} *$ than $\alpha_{1,0} . n^{*}$ value changes as $\gamma$ value increases from 0.5 to 0.6 , and the change in $n^{*}$ has caused $T_{\mathrm{A}} *$ to decline sharply.

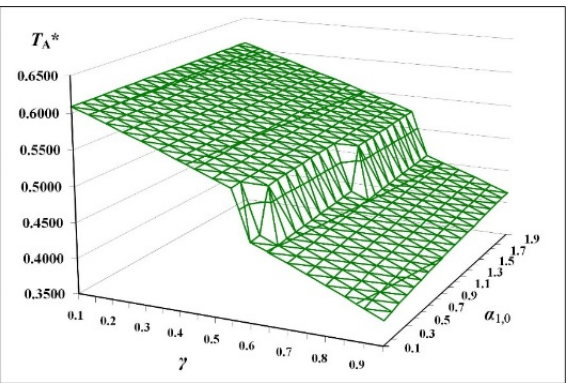

Fig. 14. The combined influence on $T_{\mathrm{A}}{ }^{*}$ regarding $\gamma$ and $\alpha_{1,0}$

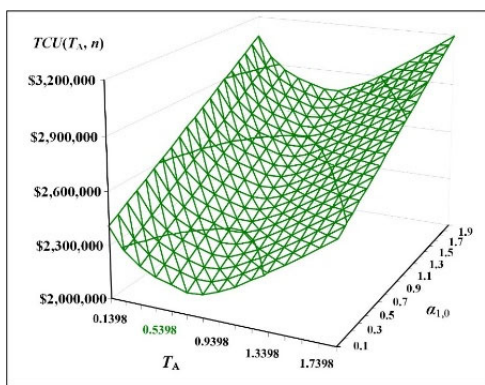

Fig. 15. The behavior of $\operatorname{TCU}\left(T_{\mathrm{A}}, n\right)$ relating to $T_{\mathrm{A}}$ and $\alpha_{1,0}$ 
Moreover, Figure 15 illustrates $T C U\left(T_{\mathrm{A}}, n\right)$ 's behavior relating to $T_{\mathrm{A}}$ and $n$. As the adjustable-rate added output proportion $\alpha_{1,0}$ rises, $T C U\left(T_{\mathrm{A}}, n\right)$ upsurges significantly. As $T_{\mathrm{A}}$ departs from the optimal value of $T_{\mathrm{A}}{ }^{*}, T C U\left(T_{\mathrm{A}}, n\right)$ rises in both directions.

\section{Conclusions}

The present study applies the mathematical method to construct a delayed differentiation two-stage model for exploring a multiproduct manufacturer-retailer coordinated supply chain system with an adjustable rate for making common parts and a multi-shipment plan for shipping the finished goods. The Hessian matrix equations assist us in optimizing the problem's cost-minimization fabrication-shipment decision. An example shows the applicability and capability of our model numerically. This study's significant contribution includes the following:

(1) It develops an exact model to represent and explore a delayed differentiation multiproduct manufacturer-retailer coordinated system with real-life characteristics;

(2) It numerically demonstrates the proposed model's applicability and capability by disclosing various crucial systemrelating characteristics that can facilitate managerial decision-making.

The impact of incorporating an adjustable rate in stage two for making finished products in the system will be a worthy investigating work.

\section{Acknowledgment}

The authors truly appreciate the Ministry of Science and Technology of Taiwan for supporting this study (fund\#: MOST 1072410-H-324-002).

\section{References}

Astuty, W., Zufrizal, Pasaribu, F., \& Rahayu, S. (2021). The effects of customer relationship management, human resource competence and internal control systems on the effectiveness of supply chain management in the Indonesian public sector. Uncertain Supply Chain Management, 9(3), 595-602.

Brahmi, A., Hadj-Alouane, A.B., \& Sboui, S. (2020). Dynamic and reactive optimization of physical and financial flows in the supply chain. International Journal of Industrial Engineering Computations, 11(1), 83-106.

Chiu, S.W., Wu, H.Y., Chiu, T., \& Chiu, Y.-S.P. (2021). Multi-item production lot sizing with postponement, external source for common parts, and adjustable rate for end products. International Journal of Mathematical, Engineering and Management Sciences, 6(3), 787-804.

Davis, T., \& Sasser, M. (1995). Postponing product differentiation. Mechanical Engineering, 117(11), 105-107.

Dellagi, S., Chelbi, A., \& Trabelsi, W. (2017). Joint integrated production-maintenance policy with production plan smoothing through production rate control. Journal of Manufacturing Systems, 42, 262-270.

Ekin, T., \& Aktekin, T. (2021). Decision making under uncertain and dependent system rates in service systems. European Journal of Operational Research, 291(1), 335-348.

Fatehi-Kivi, A., Mehdizadeh, E., Tavakkoli-Moghaddam, R., \& Najafi, E. (2021). Solving a Multi-Item Supply Chain Network Problem by Three Meta-heuristic Algorithms. Journal of Optimization in Industrial Engineering, 14(2), 145151.

Frank, M., Ostermeier, M., Holzapfel, A., Hübner, A., \& Kuhn, H. (2021). Optimizing routing and delivery patterns with multi-compartment vehicles. European Journal of Operational Research, 293(2), 495-510.

Garcia, A., Leal, M., \& Lee, S.-H. (2020). Cooperation with a multiproduct corporation in a strategic managerial delegation. Managerial and Decision Economics, 41(1), 3-9.

Graman, G.A. (2010) A partial-postponement decision cost model. European Journal of Operational Research, 201(1), 3444.

İnkaya, T., Armbruster, D., Li, H., \& Kempf, K.G. (2018). Product variety strategies for vertically differentiated products in a two-stage supply chain. International Journal of Production Research, 56(17), 5930-5944.

Katayama, H. (1998). An integrated management procedure of multi-item mixed-line production system - Its hierarchical structure and performance evaluation. International Journal of Production Research, 36(10), 2633-2651.

Martins, L.D.C., Gonzalez-Neira, E.M., Hatami, S., Juan, A.A., \& Montoya-Torres, J.R. (2021). Combining production and distribution in supply chains: The hybrid flow-shop vehicle routing problem. Computers and Industrial Engineering, 159 , Art. No. 107486.

Nahmias, S. (2009). Production \& Operations Analysis. McGraw-Hill, New York, 183-205.

Ohmori, S., \& Yoshimoto, K. (2021). Multi-product multi-vehicle inventory routing problem with vehicle compatibility and site dependency: A case study in the restaurant chain industry. Uncertain Supply Chain Management, 9(2), $351-362$.

Ongcunaruk, W., Ongkunaruk, P., \& Janssens, G.K. (2021). Genetic algorithm for a delivery problem with mixed time windows. Computers and Industrial Engineering, 159, Art. No. 107478.

Pando, V., San-José, L.A., Sicilia, J., \& Alcaide-López-de-Pablo, D. (2021). Maximization of the return on inventory management expense in a system with price- and stock-dependent demand rate. Computers and Operations Research, 127, Art. No. 105134. 
Quetschlich, M., Moetz, A., \& Otto, B. (2021). Optimisation model for multi-item multi-echelon supply chains with nested multi-level products. European Journal of Operational Research, 290(1), 144-158.

Rajagopalan, S., \& Swaminathan, J.M. (2001). A coordinated production planning model with capacity expansion and inventory management. Management Science, 47(11), 1562-1580.

Rardin, R.L. (1998). Optimization in Operations Research. Prentice-Hall; New Jersey, USA.

Samuel, C.N., Diallo, C., Venkatadri, U., \& Ghayebloo, S. (2021). Multicomponent multiproduct closed-loop supply chain design with transshipment and economies of scale considerations. Computers and Industrial Engineering, 153, Art. No. 107073.

Schneider, H., \& Rinks, D.B. (1989). Optimal policy surfaces for a multi-item inventory problem. European Journal of Operational Research, 39(2), 180-191.

Sharma, S. (2008). A modification for the carrying cost estimation with respect to the flexibility in production rate. International Journal of Advanced Manufacturing Technology, 36(11-12), pp. 1252-1260.

Sheikh, S., Komaki, G.M., Kayvanfar, V., \& Teymourian, E. (2019). Multi-Stage assembly flow shop with setup time and release time. Operations Research Perspectives, 6(2019), Art. No. 100111, 1-15.

Tolooie, A., Maity, M., \& Sinha, A.K. (2020). A two-stage stochastic mixed-integer program for reliable supply chain network design under uncertain disruptions and demand. Computers and Industrial Engineering, 148, Art. No. 106722

Weskamp, C., Koberstein, A., Schwartz, F., Suhl, L., \& Voß, S. (2019). A two-stage stochastic programming approach for identifying optimal postponement strategies in supply chains with uncertain demand. Omega, 83, 123-138.

Yang, J., Yan, H., \& Taksar, M.I. (2000). Optimal production and setup scheduling: A one-machine, two-product system. Annals of Operations Research, 98(1-4), 291-311.

\section{Appendix - A}

\section{Table A-1}

The assumed values of corresponding variables in a single-stage scheme

\begin{tabular}{ccccccccc}
\hline Product $i$ & $K_{D, i}$ & $\lambda_{i}$ & $h_{1, i}$ & $C_{\mathrm{D}, i}$ & $C_{i}$ & $h_{3, i}$ & $P_{1, i}$ & $K_{i}$ \\
\hline 1 & $\$ 1800$ & 3000 & $\$ 16$ & $\$ 0.1$ & $\$ 80$ & $\$ 70$ & 58000 & $\$ 17000$ \\
2 & $\$ 1900$ & 3200 & $\$ 18$ & $\$ 0.2$ & $\$ 90$ & $\$ 75$ & 59000 & $\$ 17500$ \\
3 & $\$ 2000$ & 3400 & $\$ 20$ & $\$ 0.3$ & $\$ 100$ & $\$ 80$ & 60000 & $\$ 18000$ \\
4 & $\$ 2100$ & 3600 & $\$ 22$ & $\$ 0.4$ & $\$ 110$ & $\$ 85$ & 61000 & $\$ 18500$ \\
5 & $\$ 2200$ & 3800 & $\$ 24$ & $\$ 0.5$ & $\$ 120$ & $\$ 90$ & 62000 & $\$ 19000$ \\
\hline
\end{tabular}


(C) 2022 by the authors; licensee Growing Science, Canada. This is an open access article distributed under the terms and conditions of the Creative Commons Attribution (CCBY) license (http://creativecommons.org/licenses/by/4.0/). 